\title{
Evaluation of melatonin and AFMK levels in women with breast cancer
}

\author{
Tialfi Bergamin de Castro ${ }^{1}$ - Newton Antônio Bordin-Junior ${ }^{2}$. Eduardo Alves de Almeida ${ }^{3}$. \\ Debora Aparecida Pires de Campos Zuccari $\mathbb{B}^{1,2}$
}

Received: 12 March 2018 / Accepted: 2 May 2018 / Published online: 24 May 2018

(c) Springer Science+Business Media, LLC, part of Springer Nature 2018

\begin{abstract}
Purpose Changes in the circadian rhythm may contribute to the development of cancer and are correlated with the high risk of breast cancer (BC) in night workers. Melatonin is a hormone synthesized by the pineal gland at night in the absence of light. Levels of melatonin and the metabolite of oxidative metabolism AFMK (acetyl-N-formyl-5-methoxykynurenamine), are suggested as potential biomarkers of $\mathrm{BC}$ risk. The aims of this study were to evaluate levels of melatonin and AFMK in women recently diagnosed with $\mathrm{BC}$, women under adjuvant chemotherapy, and night-shift nurses, and compare them with healthy women to evaluate the relation of these compounds with BC risk.

Methods Blood samples were collected from 47 women with BC, 9 healthy women, 10 healthy night shift nurses, and 6 patients under adjuvant chemotherapy. Compound levels were measured by mass spectrometry.

Results and conclusions Our results showed that women with BC had lower levels of melatonin compared to control group women, and even lower in night-shift nurses and in patients under adjuvant chemotherapy. There was no significant difference of AFMK levels between the groups. In addition to this, high levels of melatonin and AFMK were related to patients with metastasis, and high levels of AFMK were related to the presence of lymph node-positive, tumor $>20 \mathrm{~mm}$ and patients who sleep with light at night. Our results showed a reduction of melatonin levels in BC patients, suggesting a relation with the disease, and in addition, point to the importance of melatonin supplementation in women that work at night to reduce the $\mathrm{BC}$ risk.
\end{abstract}

Keywords Breast cancer $\cdot$ Circadian rhythmic $\cdot$ Melatonin $\cdot$ AFMK $\cdot$ Blood level

\section{Introduction}

Breast cancer is the most frequent type of cancer in women worldwide. High risk of $\mathrm{BC}$ development has been related to the breakdown of the circadian cycle by shift work and the presence of artificial light at night, a common factor in modern life [1]. Circadian rhythmic disruption can block the

$\triangle$ Debora Aparecida Pires de Campos Zuccari

debora.zuccari@famerp.br

1 São Paulo State University - UNESP, Cristóvão Colombo, 2265, São José do Rio Preto, 15054-000 São Paulo, Brazil

2 São José do Rio Preto Medical School - FAMERP, Av. Brigadeiro Faria Lima, 5416, São José do Rio Preto, 15090-000 São Paulo, Brazil

3 Regional University of Blumenau Foundation - FURB, Antônio da Veiga, 140, Blumenau, 89030-903 Santa Catarina, Brazil nightly production of melatonin ( $N$-acetyl-5-methoxytryptamine), an endogenous hormone synthesized from serotonin by the pineal gland during the night $[2,3]$. Serotonin is acetylated to $N$-acetylserotonin by the enzyme arylakylamine $N$-acetyltransferase (AANAT) and is then converted into melatonin by the enzyme hydroxyindole- $O$ methyl-transferase (HIOMT). Melatonin production follows a rhythmic pattern with secretory peak between 3 a.m. and 4 a.m. in the absence of light, and once secreted, it is distributed to various body tissues and organs and is not stored $[4,5]$. The light stimulus in the retina inhibits the action of AANAT, inhibiting the conversion of serotonin into $\mathrm{N}$ acetylserotonin and consequently blocking melatonin production [6, 7].

Three main pathways are described to melatonin degradation: (i) indolic pathway, (ii) alternative indolic pathways, and (iii) kynuric pathway that produce $N^{1}$-acetyl- $N^{2}$-formyl-5methoxykynuramine (AFMK), which involves melatonin oxidative pyrrole-ring cleavage. A study by Ferri and colleagues 
(2005) indicates that the conversion by kynuric pathway can reach one-third of melatonin catabolism [2, 8, 9].

In the kynuric pathway, studies have shown that melatonin acts as an antioxidant by interacting with free radicals. AFMK is also a potent antioxidant, as effective as melatonin, and its synthesis can occur by enzymatic action of indoleamine-2,3-dioxygenase (IDO1) and reactive oxidative species (ROS) [10, 11]. Following the antioxidative cascade, AFMK can be further converted to AMK ( $N$-acetyl-5methoxykynuramine) by $N$-deformylation [12].

Several actions related with physiological, metabolic, and behavioral events are described to melatonin, such as regulation of endocrine phenomena independent of the hypothalamic-pituitary-gonadal axis, thermoregulation, regulation of the cardiovascular system, activity-rest and wake-sleep cycles, immune system, growth, and aging [2, 10, 13, 14]. Melatonin also has important functions in cancer, showing oncostatic and oncoprotective effects on breast tumors, which include cell cycle regulation, inhibition of proliferation and promotion of apoptosis, a role in DNA repair and tumor suppression by angiogenesis and metastasis inhibition. [2, 15-17]

Melatonin low levels can be related with the risk of cancer development, principally in night workers [1, 2]. In 2001, Schernhammer and colleagues showed that night shift workers have increased risk of BC development [18]. Following this, the World Health Organization designated nightshift work as a risk factor for the development of BC [19].

As described, melatonin has inhibitory and antiproliferative effects on tumor cells and, as the molecule of AFMK, have potent antioxidant capacity, both act to reduce harmful effects caused by oxidative stress through exposure to night light and/or by tumor cells. According to the literature, it seems clinically relevant to evaluate the levels of melatonin and AFMK in BC patients and high-risk women (night work). Thus, in this study, we evaluated the serum levels of melatonin and its metabolite AFMK in women with recently diagnosed $\mathrm{BC}$ and under adjuvant chemotherapy, compared with healthy women to evaluate the relation with BC development and action as antioxidant caused by chemotherapy. Nurses working night-shifts were evaluated to verify the influence of light at night on melatonin and AFMK levels. In addition, the levels of melatonin and AFMK were compared with the clinical pathological characteristics of $\mathrm{BC}$ patients to verify its potential correlation with prognosis.

\section{Material and methods}

\section{Blood samples}

The project was approved by the ethics committee of São José do Rio Preto Medical School (number 682.062).
Approximately $10 \mathrm{~mL}$ of blood was collected in tubes with EDTA anticoagulant from a total of $47 \mathrm{BC}$ patients (mean age 57), without treatment or surgery, diagnosed at the Gynecology and Obstetrics Service of the Cancer Institute of the Hospital de Base of São José do Rio Preto, São Paulo, Brazil; in addition, ten blood samples were taken from nurses that work exclusively at night and six samples from woman diagnosed with BC during adjuvant chemotherapy. The control group consisted of blood samples from nine women with no history of cancer paired with BC patients by age. All women signed informed consent term and were asked about the quality of sleep and the amount of light in the room at night. The samples were collected between 7 a.m. and 9 a.m., because of the stop synthesis of the compounds at the beginning of the photoperiod of the day, consequently, its level decreases during the day. Plasma was separated and immediately stored at $-80^{\circ} \mathrm{C}$ for further extraction.

The tumor type and subtype, including TNM information (tumor size, lymph node involvement, and metastases) were collected in the Pathology Service of the Hospital de Base of São José do Rio Preto.

\section{Melatonin and AFMK extraction}

Plasma samples were thawed and transferred to a $15 \mathrm{~mL}$ falcon tube in ice and protected from light. Dichloromethane 1:1 was added and the samples were vigorously vortexed. Subsequently, samples were centrifuged at $6500 \mathrm{rpm}$ for $10 \mathrm{~min}$ at $4{ }^{\circ} \mathrm{C}$ and the organic phase (bottom) was separated into a $2 \mathrm{~mL}$ tube. The dichloromethane was dried in nitrogen gas and samples were stored in at $-80^{\circ} \mathrm{C}$ for further analysis.

\section{Dosage of melatonin and AFMK by mass spectrometry}

A mass spectrometry system coupled to an HPLC (High Performance Liquid Chromatography) was used (model Xevo ${ }^{\oplus}$ TQ-S -Waters, Milford, Massachusetts, EUA) with a Phenomenex ${ }^{\oplus} \mathrm{C} 18(100 \times 4.6 \mathrm{~mm}, 2.7 \mu \mathrm{m})$ column.

HPLC conditions were set in gradient with $\mathrm{A}\left(\mathrm{H}_{2} \mathrm{O}+\right.$ formic acid $0.1 \%$ ) and $\mathrm{B}$ (acetonitrile + formic acid $0.1 \%$ ) and $50 \%$ of B for $5 \mathrm{~min}, 90 \%$ of B for $2 \mathrm{~min}$ and $50 \%$ of B until $15 \mathrm{~min}$. The dried samples were re-suspended in $150 \mu \mathrm{l}$ of acetonitrile. The injection volume was $10 \mu \mathrm{L}$ for the standards and for the samples.

Mass spectrometer conditions were set in capillary voltage $320 \mathrm{kV}$, font temperature $150{ }^{\circ} \mathrm{C}$, desolvation gas temperature (N2) $350{ }^{\circ} \mathrm{C}$, desolvation gas flow $600 \mathrm{~L} / \mathrm{h}$, collision gas $0.15 \mathrm{~mL} / \mathrm{min}$. The settings for reading the molecules were established by MRM (multiple reaction monitoring) for melatonin (233.1>174.1—cone voltage $35 \mathrm{~V}$, collision energy $13 \mathrm{eV}-$ dwell time $=0.412 \mathrm{~s}$ ) and for 
AFMK $(287.1>228.1-$ cone voltage $40 \mathrm{~V}$, collision energy $15 \mathrm{eV}-$ dwell time $=0.412 \mathrm{~s}$ ).

For quantification, a standard curve was performed with 11 points of melatonin and AFMK standard concentrations between $1 \mathrm{pg} / \mathrm{ml}$ and $200 \mathrm{pg} / \mathrm{ml}$ and the curve equation was used to determine the concentration of these molecules in samples by the peak area of each compound. Both curves presented $R^{2}>0.99$.

\section{Chemicals}

Melatonin, acetonitrile, and dichloromethane were purchased from Sigma Aldrich (St. Louis, Missouri, EUA) and AFMK from Cayman Chemical Company (Ann Arbor, Michigan, EUA).

\section{Statistical analysis}

The results were subjected to statistical analysis using GraphPad Prism 6.0 software (GraphPad, La Jolla, CA, USA). Levels of melatonin and AFMK between groups (control, BC patients, shift work nurses, and women under adjuvant chemotherapy) and between different clinicopathological data were compared by Mann-Whitney or paired- Student $t$-test. Multiple comparison analysis was performed using one-way ANOVA followed by Bonferroni. Spearman correlation was performed to evaluate the correlation of metabolite levels and age of the patients, tumor status of ER, TNM, quality of sleep, and room light at night. The results were considered statistically significant when $p$ was $<0.05$. Data are pretended with mean \pm standard error of the mean (S.E.M.).

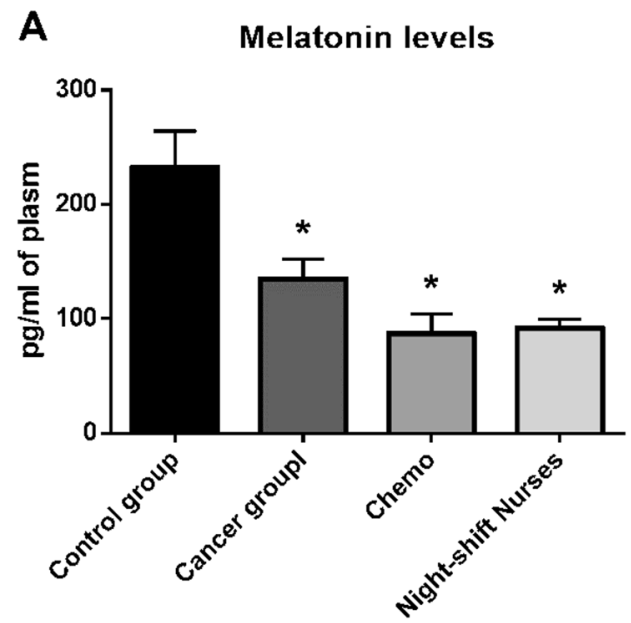

Fig. 1 Levels of melatonin (a) and AFMK (b) in control group, BC group, night shift workers, and women in chemotherapy (chemo). Control group has higher level of melatonin than cancer group, women in adjuvant chemotherapy (chemo) and night-shift nurses. AFMK

\section{Results}

\section{Plasmatic level of melatonin and AFMK in women with breast cancer}

Levels of melatonin and its metabolites were evaluated in BC patients, night shift nurses and women in adjuvant chemotherapy, and compared with healthy women, considered the control group. In group analysis, melatonin levels were higher and statistically different in control group compared with women from the other groups $(p \leq 0.05)$, while AFMK levels did not present significant differences between experimental groups $(p>0.05)$ (Fig. 1a, b, respectively). In paired test, women with cancer were paired with control group according to age and sleep quality. Paired $t$-test showed that there was a statistically significant difference (higher in control group than cancer group) between melatonin levels ( $p<0.001$; Fig. 2).

Melatonin levels were also significantly lower in women with cancer and metastasis when compared with women with cancer but without metastasis $(p<0.05)$. There was no difference between melatonin levels and T1 vs. $T \geq 2$ primary tumor size, presence of lymph node involvement or not, and although there was a tendency to have a higher concentration in the group of women with cancer who sleep without light at night, it was not statistically significant in relation to women who sleep with some light source $(p>0.05)$.

When comparing AFMK levels between groups with no metastasis and presence of metastasis (M0 and M1, respectively), tumor size $(T<1$ and $T \geq 2)$, and lymph node involvement ( $\mathrm{N} 0$ for no involvement and N1 for involvement), AFMK were significantly higher $(p<0.05)$ in M1,

\section{B AFMK levels}

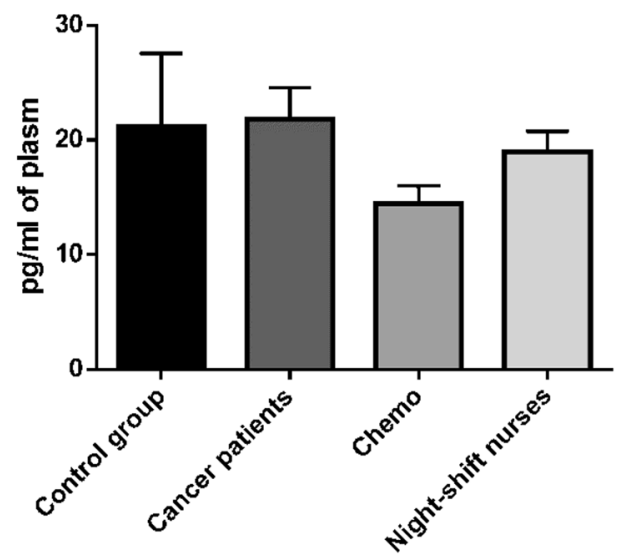

levels did not differ between groups, despite a tendency to decrease in the group undergoing chemotherapy. *Indicates statistical difference compared to the control group $(p<0.05)$ 


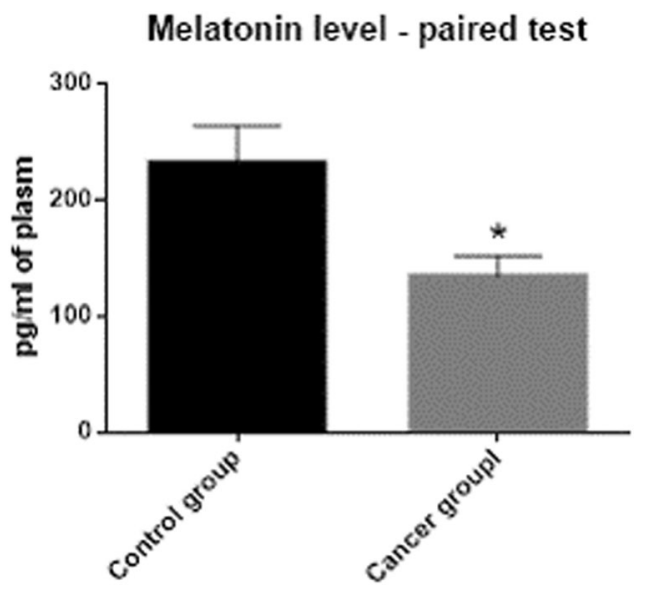

Fig. 2 Melatonin levels between control group and BC women paired by age and sleep quality. *Indicates statistical difference compared to the control group $(p<0.05)$

$T \geq 2$, and N1 and in patients who sleep with no light in the room at night.

Regarding the clinical pathological characteristics of $\mathrm{BC}$ patients, results showed that melatonin levels were significantly higher in patients with distant metastasis $(p=$ 0.02 ; Table 1), and there was no correlation with the other characteristics $(p>0.05$; Table 1). High levels of AFMK were related to tumor size higher than $2 \mathrm{~mm}(T \geq 2)$, regional lymph node-positive and metastasis $(p<0.05$, Table 1). Moreover, a significant correlation between a low level of AFMK and the presence of a considerable light source in the room at night $(p<0.05)$ was also observed.

\section{Spearman correlation test}

A statistically significant correlation was observed between melatonin and AFMK levels and the clinical pathological characteristics, sleep quality, and presence of light in room at night using the Spearman correlation test. A negative correlation was found between age and sleep quality at night before blood collection. In addition, positive correlations were found between levels of melatonin and AFMK with the presence of metastasis and there was a positive correlation between light in the room at night and sleep quality the night before blood collection (Table 2).

\section{Discussion}

The master biological clock located in the suprachiasmatic nucleus receives information about the photoperiod and controls the circadian cycle and melatonin synthesis [2, 20, 21]. Thus, the increase of melatonin levels at night informs the body that it is nighttime and restores the metabolic and homeostatic state to normal rates [22].
Table 1 Mean levels of melatonin and AFMK and its correlation with clinical, pathological, and sleep characteristics of patients with breast cancer

\begin{tabular}{|c|c|c|c|}
\hline & \multirow[t]{2}{*}{ Number of patients } & \multicolumn{2}{|c|}{ Mean (pg/ml of plasma) } \\
\hline & & melatonin & AFMK \\
\hline \multicolumn{4}{|l|}{ Patient age } \\
\hline$\leq 50$ & $14(31 \%)$ & 183.3 & 22.1 \\
\hline$>50$ & $31(69 \%)$ & 175.3 & 19.8 \\
\hline$p$-value & & 0.22 & 0.99 \\
\hline \multicolumn{4}{|c|}{ ER (estrogen receptor) } \\
\hline Positive & $32(71 \%)$ & 179.1 & 21.7 \\
\hline Negative & $13(29 \%)$ & 174.5 & 17.62 \\
\hline$p$-value & & 0.62 & 0.48 \\
\hline \multicolumn{4}{|l|}{ Tumor size } \\
\hline $\mathrm{T} 1$ & $9(20 \%)$ & 162.1 & 10.43 \\
\hline$T \geq 2$ & $36(80 \%)$ & 181.7 & 23.04 \\
\hline$p$-value & & 0.60 & $0.02^{*}$ \\
\hline \multicolumn{4}{|c|}{ Regional lymph nodes } \\
\hline No & $22(49 \%)$ & 163.1 & 13.8 \\
\hline$N \geq 1$ & $23(51 \%)$ & 191.8 & 27.0 \\
\hline$p$-value & & 0.53 & $0.03 *$ \\
\hline \multicolumn{4}{|l|}{ Metastasis } \\
\hline M0 & $36(80 \%)$ & 158.7 & 18.6 \\
\hline M1 & $9(20 \%)$ & 254.1 & 28.3 \\
\hline$p$-value & & $0.02 *$ & $0.01 *$ \\
\hline \multicolumn{4}{|c|}{${ }^{\mathrm{a}}$ General sleep quality } \\
\hline Good & $32(71 \%)$ & 190.8 & 19.1 \\
\hline Poor & $13(29 \%)$ & 145.6 & 24.0 \\
\hline$p$-value & & 0.30 & 0.85 \\
\hline \multicolumn{4}{|c|}{${ }^{a}$ Light at night } \\
\hline Dark & $23(51 \%)$ & 198.2 & 26.8 \\
\hline With light & $22(49 \%)$ & 156.5 & 13.9 \\
\hline$p$-value & & 0.27 & $0.03^{*}$ \\
\hline \multicolumn{4}{|c|}{ 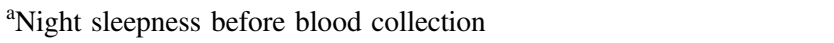 } \\
\hline Good & $23(51 \%)$ & 186.0 & 22.7 \\
\hline Poor & $22(49 \%)$ & 169.2 & 18.2 \\
\hline$p$-value & & 0.88 & 0.57 \\
\hline
\end{tabular}

* Significant value to $t$-test

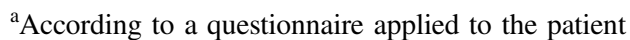

Melatonin is an important tumor suppressor and its production in the nocturnal period is directly related to the expression of clock genes (e.g., Per1, Per2, Bmal, Clock, Cry1) and its deregulation by circadian cycle breakdown, therefore, low melatonin production causes increased replication errors and mutations in DNA. Thus, circadian cycle deregulation inhibits tumor suppression functions of melatonin in diverse tissues, including breast. [1, 23-25] According to these studies, lower levels of melatonin are 
Table 2 Spearman correlation test between variables: melatonin, AFMK, and AMK levels; age; TNM; general sleep quality; light in the room at night and sleep quality last night

\begin{tabular}{lll}
\hline & $r$-value & $p$-value \\
\hline Age vs. sleep quality last night & -0.303 & 0.04 \\
Melatonin level vs. Metastasis & 0.306 & 0.04 \\
AFMK level vs. Metastasis & 0.487 & 0.01 \\
Melatonin level vs. AFMK level & 0.487 & $<0.01$ \\
Sleep quality last night ${ }^{\text {a }}$ vs. light at night & 0.377 & 0.01 \\
\hline
\end{tabular}

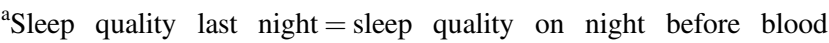
collection

related to the increased risk of developing cancer, including $\mathrm{BC}$, and these data corroborate with our findings showing a lower level of melatonin in women with $\mathrm{BC}$ compared to women without a history of cancer (control group) independent of sleep quality and presence of light in the room at night. Further, our results were corroborated by Tamarkin (1982) in patients with BC with ER-negative tumor [26].

Several studies indicate that bright light, up to 2500 lux, and devices with light source at night also alter melatonin levels [27-32]. In fact, recently the increased risk of BC has been associated with night workers, which is related with the interruption of melatonin production [7]. According to the study by Cordina-Diverger and collaborators (2018), pre-menopausal women have increased risk of BC development when there is a high and long exposure to light at night [33]. Therefore, women who work during the night may have increased risk of developing $\mathrm{BC}$ due to constant lowered melatonin levels. Our results corroborate these data, which showed low levels of melatonin in night shift nurses in comparison to women without a history of cancer and without nocturnal activities. In addition, elevated levels of AFMK were related to women who slept without a light source in their bedroom at night. The absence of light may contribute to the increase in melatonin levels and consequently higher metabolism in AFMK, which may explain the high level of this metabolite.

Regarding the clinical pathological factors, a study by Bartsch and colleagues (1989) showed that the level of nocturnal melatonin was inversely proportional to the size of breast tumors in women [34], however, there was no correlation between tumor size and melatonin levels in our study. Nevertheless, patients with tumors $>20 \mathrm{~mm}(T \geq 2)$ had higher AFMK levels than patients with T1. Perhaps due to the higher oxidation rate of melatonin due to the stress caused by the increased number of tumor cells.

Numerous anticancer effects of melatonin are established in the literature, including antiestrogenic [35, 36], antiproliferative [37, 38], anti-metastatic [39, 40], pro-apoptotic [41-43], antioxidant [44-46], anti-angiogenic [1, 16] and immuno-enhancing effects [47, 48]. Moreover, González-
González and colleagues in 2018, after a review of the literature, conclude that there is evidence that melatonin might be an important treatment against high risk of BC [49]. These studies highlight the protective action of melatonin in $\mathrm{BC}$, suggesting a function of reducing the risk of developing this type of neoplasia.

Following the melatonin relation to downregulation of metastasis-related genes and key genes in angiogenesis [2], in our study melatonin levels were not correlated with ER status, However, higher levels of melatonin and AFMK were correlated with the presence of distant metastasis and AFMK level with lymph node involvement $(N>0)$. There is no evidence of high levels of melatonin and AFMK in cancer metastasis. Our supposition is that $\mathrm{T}$ lymphocytes produce all the enzymes necessary to synthesize considerable levels of melatonin. Thus, it is suggested that the invasion of lymph node and other tissues by tumor cells can increase the local immune response and, as a consequence, increase the melatonin levels. [48, 50-52] In addition, tumor cells in the lymph nodes increase the expression of IDO1 enzyme that suppresses the action of T lymphocytes, through the activation of regulatory $\mathrm{T}$ cells $\left(\mathrm{T}_{\text {reg }}\right)$, that escape from the host immune system. This enzyme is involved in one of the main pathways that catabolize the conversion of indoleamines (tryptophan, serotonin, and melatonin) into kynurenines (formylkynurenine, formyl-5hydroxykynurenamine, and AFMK, respectively) [53-57]. This data can explain the high levels of AFMK observed in patients with lymph node-positive, and metastasis could be a consequence of the melatonin production by the local immune cells. It is known that several actions of melatonin occur through its membrane receptors coupled to $\mathrm{G}$ proteins (MT1 and MT2), but because it is lipophilic, melatonin can also cross the cell membrane acting directly in modulation of intracellular proteins and performing antioxidant activity [9]. The antioxidant action of melatonin is related to tissue protection by eliminating ROS and nitrogen species, and, in the activation of antioxidant enzymes such as superoxide dismutase (SOD), catalase (CAT), glutathione peroxidase (GPx), and glutathione reductase (GR). When this antioxidant action occurs, the conversion of melatonin into AFMK also occurs, independent of enzymatic action [10]. In this context, we found that patients under adjuvant chemotherapy showed lower levels of melatonin compared to control group women, which can be related with its antioxidant potential against the oxidative stress and cell death caused by chemotherapy.

AFMK is a potent antioxidant and it can be deformylated by arylamine formamidase or hemoperoxidase to AMK [9]. In addition to the antioxidant action, AFMK also has antiinflammatory functions in acute pancreatitis and it can also control melanocytes in vitro [10]. Treatment with high doses of AFMK in pancreatic cancer cell line (PANC-1) 
increased heat shock proteins (HSP), which are related to control of proliferation and protection against cell damage [58]. There are few studies in the literature relating the AFMK with cancer.

In conclusion, our results show that melatonin serum levels are lower in BC patients and in nurses that work at night, indicating a possible factor that may be related to the risk of cancer. In addition, higher levels of melatonin and AFMK are related with clinical pathological characteristics of the BC patients, such as metastasis and lymph nodepositive, suggesting a relationship with inflammatory response. Taken together, our results suggest that the maintenance of the circadian cycle and the absence of light sources at night, and therefore normal levels of melatonin and AFMK, are important factors that may indicate the risk of BC development. The analysis of serum levels of melatonin can be an important tool for the normalization of concentration through supplementation available today, both in women with low levels and in women working at night.

Acknowledgements We are grateful for the grant \#2015/02935-2, from São Paulo Research Foundation (FAPESP), grant \#003/2015, FAPERP-Foundation to Support Research and Extension of São José do Rio Preto and Professor Luis Albeto Beraldo de Moraes for ceding Spectrometry Laboratory of Pharmaceutical Sciences Faculty of Mass Ribeirão Preto-University of São Paulo to perform the analysis and thank Dr. Eduardo José Crevelin for the support.

Author contributions All authors contributed significantly to the performance of work.

Funding This study was funded by FAPESP-São Paulo Research Foundation (\# 2015/02935-2) and FAPERP-Foundation to Support Research and Extension of São José do Rio Preto (Proc. 003/2015). This work was supported by the São Paulo Research Foundation (FAPESP) (grant \#2015/02935-2).

\section{Compliance with ethical standards}

Conflict of interest The authors declare that they have no conflict of interest.

Ethical approval All procedures performed in studies involving human participants were in accordance with the ethical standards of the institutional and/or national research committee and with the 1964 Helsinki declaration and its later amendments or comparable ethical standards.

Informed consent Informed consent was obtained from all individual participants included in the study.

\section{References}

1. R.G. Stevens, G.C. Brainard, D.E. Blask, S.W. Lockley, M.E. Motta, Breast cancer and circadian disruption from electric lighting in the modern world. CA Cancer J. Clin. 64, 207 (2014)
2. S.M. Hill, V.P. Belancio, R.T. Dauchy, S. Xiang, S. Brimer, L. Mao, A. Hauch, P.W. Lundberg, W. Summers, L. Yuan, T. Frasch, D.E. Blask, Melatonin: An inhibitor of breast cancer. Endocr. Relat. Cancer 22, R183 (2015)

3. Z. Xie, F. Chen, W.A. Li, X. Geng, C. Li, X. Meng, Y. Feng, W. Liu, F. Yu, A review of sleep disorders and melatonin. Neurol. Res. 6412, 1 (2017)

4. Ja.S. Neto, B.F. De Castro, Melatonina, ritmos biológicos e sono -uma revisão da literatura. Rev. Bras. Neurol. 44, 5 (2008)

5. R.J. Reiter, Pineal melatonin: Cell biology of its synthesis and of its physiological interactions. Endocr. Rev. 12, 151 (1991)

6. J. Espino, J.A. Pariente, A.B. Rodríguez, Oxidative stress and immunosenescence: Therapeutic effects of melatonin. Oxid. Med. Cell Longev. 2012, 1 (2012)

7. V. Srinivasan, G. Maestroni, D. Cardinali, A. Esquifino, S.P. Perumal, S. Miller, Melatonin, immune function and aging. Immun. Ageing 5, 109 (2011)

8. G. Ferry, C. Ubeaud, P.-H. Lambert, S. Bertin, F. Cogé, P. Chomarat, P. Delagrange, B. Serkiz, J.-P. Bouchet, R.J.W. Truscott, J.A. Boutin, Molecular evidence that melatonin is enzymatically oxidized in a different manner than tryptophan: Investigations with both indoleamine 2,3-dioxygenase and myeloperoxidase. Biochem. J. 388, 205 (2005)

9. M.L. Dubocovich, P. Delagrange, D.N. Krause, D. Sugden, D.P. Cardinali, J. Olcese, Nomenclature, classification, and pharmacology of $\mathrm{G}$ protein-coupled melatonin receptors. Pharmocological. Rev. 62, 343 (2010)

10. J. Jaworek, J. Szklarczyk, J. Bonior, M. Kot, M. Goralska, P. Pierzchalski, R.J. Reiter, U. Czech, R. Tomaszewska, Melatonin metabolite, N1-acetyl-N1-formyl-5-methoxykynuramine (AFMK), attenuates acute pancreatitis in the rat: In vivo and in vitro studies. J. Physiol. Pharmacol. 67, 411 (2016)

11. M.A. Ciorba, Indoleamine 2,3 dioxygenase in intestinal disease. Curr. Opin. Gastroenterol. 29, 146 (2013)

12. S.O. Silva, M.R. Rodrigues, S.R.Q. Carvalho, L.H. Catalani, A. Campa, V.F. Ximenes, Oxidation of melatonin and its catabolites, N1-acetyl-N 2-formyl-5-methoxykynuramine and N1-acetyl-5methoxykynuramine, by activated leukocytes. J. Pineal Res. 37, $171(2004)$

13. C.C. Maganhin, A.A.F. Carbonel, J.H. Hatty, L.F.P. Fuchs, I.S. de Oliveira-Júnior, M. de, J. Simões, R.S. Simões, E.C. Baracat, J.M. Soares Jr., Efeitos da melatonina no sistema genital feminino: Breve revisão. Rev. Assoc. Med. Bras. 54, 267 (2008)

14. R.J. Reiter, J.C. Mayo, D.X. Tan, R.M. Sainz, M. AlatorreJimenez, and L. Qin. Melatonin as an antioxidant: Under promises but over delivers. J. Pineal Res. 253, 253-278 (2016)

15. G.B. Gelaleti, T.F. Borin, L.B. Maschio-Signorini, M.G. Moschetta, B.V. Jardim-Perassi, G.B. Calvinho, M.C. Facchini, A.M. Viloria-Petit, D.A.P. de Campos Zuccari, Efficacy of melatonin, IL-25 and silL-17B in tumorigenesis-associated properties of breast cancer cell lines. Life Sci. 183, 98 (2017)

16. B.V. Jardim-Perassi, M.R. Lourenço, G.M. Doho, I.H. Grígolo, G. B. Gelaleti, L.C. Ferreira, T.F. Borin, M.G. Moschetta, D.A. Pires de Campos Zuccari, Melatonin regulates angiogenic factors under hypoxia in breast cancer cell lines. Anticancer Agents Med. Chem. 16, 347 (2016)

17. T.F. Borin, A.S. Arbab, G.B. Gelaleti, L.C. Ferreira, M.G. Moschetta, B.V. Jardim-Perassi, A. Iskander, N.R.S. Varma, A. Shankar, V.B. Coimbra, V.A. Fabri, J.G. de Oliveira, D.A.P. de C. Zuccari, Melatonin decreases breast cancer metastasis by modulating rho-associated kinase protein-1 expression. J. Pineal Res. 60, 3 (2016)

18. E.S. Schernhammer, F. Laden, F.E. Speizer, W.C. Willett, D.J. Hunter, I. Kawachi, G.A. Colditz, Rotating night shifts and risk of breast cancer in women participating in the nurses' health study. J. Natl. Cancer Inst. 93, 1563 (2001) 
19. K. Straif, R. Baan, Y. Grosse, B. Secretan, F. El Ghissassi, V. Bouvard, A. Altieri, L. Benbrahim-Tallaa, V. Cogliano; WHO International Agency For Research on Cancer Monograph Working Group, Carcinogenicity of shift-work, painting, and firefighting. Lancet Oncol. 8, 1065 (2007)

20. D.M. Berson, F.A. Dunn, M. Takao, Phototransduction by retinal ganglion cells that set the circadian clock. Science 295, 1070 (2002)

21. M.H. Hastings, A.B. Reddy, E.S. Maywood, A Clockwork web: Circadian timing in brain and periphery, in health and disease. Nat. Rev. Neurosci. 4, 649 (2003)

22. R.M. Slominski, R.J. Reiter, N. Schlabritz-Loutsevitch, R.S. Ostrom, A.T. Slominski, Melatonin membrane receptors in peripheral tissues: Distribution and functions. Mol. Cell. Endocrinol. 351, 152 (2012)

23. M.P. Antoch, V.Y. Gorbacheva, O. Vykhovanets, I.A. Toshkov, R.V. Kondratov, A.A. Kondratova, C. Lee, A.Y. Nikitin, Disruption of the circadian clock due to the clock mutation has discrete effects on aging and carcinogenesis. Cell Cycle 7, 1197 (2008)

24. M.A. Gauger, A. Sancar., Cryptochrome, circadian cycle, cell cycle checkpoints, and cancer. Cancer Res. 65, 6828 (2005)

25. S. You, P.A. Wood, Y. Xiong, M. Kobayashi, J. Du-Quiton, W.J. M. Hrushesky, Daily coordination of cancer growth and circadian clock gene expression. Breast Cancer Res. Treat. 91, 47 (2005)

26. L. Tamarkin, D. Danforth, A. Lichter, E. DeMoss, M. Cohen, B. Chabner, M. Lippman, Decreased nocturnal plasma melatonin peak in patients with estrogen receptor positive breast. Cancer Sci. 216, 1003 (1982)

27. G.C. Brainard, J.P. Hanifin, J.M. Greeson, B. Byrne, G. Glickman, E. Gerner, M.D. Rollag, Action spectrum for melatonin regulation in humans: Evidence for a novel circadian photoreceptor. J. Neurosci. 21, 6405 (2001)

28. G. Glickman, R. Levin, G.C. Brainard, Ocular input for human melatonin regulation: Relevance to breast cancer. Neuro. Endocrinol. Lett. 23(Suppl 2), 17 (2002)

29. J.R. Gaddy, M.D. Rollag, G.C. Brainard, Pupil size regulation of threshold of light-induced melatonin suppression. J. Clin. Endocrinol. Metab. 77, 1398 (1993)

30. C. Cajochen, S. Frey, D. Anders, J. Spati, M. Bues, A. Pross, R. Mager, A. Wirz-Justice, O. Stefani, Evening exposure to a lightemitting diodes (LED)-backlit computer screen affects circadian physiology and cognitive performance. J. Appl. Physiol. 110, 1432 (2011)

31. J.M. Zeitzer, D.J. Dijk, R. Kronauer, E. Brown, C. Czeisler, Sensitivity of the human circadian pacemaker to nocturnal light: Melatonin phase resetting and suppression. J. Physiol. 526(Pt 3), 695 (2000)

32. J.J. Gooley, K. Chamberlain, K.A. Smith, S.B.S. Khalsa, S.M.W. Rajaratnam, E. Van Reen, J.M. Zeitzer, C.A. Czeisler, S.W. Lockley, Exposure to room light before bedtime suppresses melatonin onset and shortens melatonin duration in humans. J. Clin. Endocrinol. Metab. 96, E463 (2011)

33. E. Cordina-Duverger, F. Menegaux, A. Popa, S. Rabstein, V. Harth, B. Pesch, T. Brüning, L. Fritschi, D.C. Glass, J.S. Heyworth, T.C. Erren, G. Castaño-Vinyals, K. Papantoniou, A. Espinosa, M. Kogevinas, A. Grundy, J.J. Spinelli, K.J. Aronson, P. Guénel. Night shift work and breast cancer: A pooled analysis of population-based case-control studies with complete work history. Eur. J. Epidemiol. 1, 1-11 (2018)

34. C. Bartsch, H. Bartsch, U. Fuchs, T.H. Lippert, O. Bellmann, D. Gupta, Stage-dependent depression of melatonin in patients with primary breast cancer. Correlation with prolactin, thyroid stimulating hormone, and steroid receptors. Cancer 64, 426 (1989)

35. S.M. Hill, C. Cheng, L. Yuan, L. Mao, R. Jockers, B. Dauchy, T. Frasch, D.E. Blask, Declining melatonin levels and MT1 receptor expression in aging rats is associated with enhanced mammary tumor growth and decreased sensitivity to melatonin. Breast Cancer Res. Treat. 127, 91 (2011)

36. R.T. Dauchy, S. Xiang, L. Mao, S. Brimer, M.A. Wren, L. Yuan, M. Anbalagan, A. Hauch, T. Frasch, B.G. Rowan, D.E. Blask, S. M. Hill, Circadian and melatonin disruption by exposure to light at night drives intrinsic resistance to tamoxifen therapy in breast cancer. Cancer Res. 74, 4099 (2014)

37. D.E. Blask, D.B. Pelletier, S.M. Hill, A. Lemus-Wilson, D.S. Grosso, S.T. Wilson, M.E. Wise, Pineal melatonin inhibition of tumor promotion in the $\mathrm{N}$-nitroso-N-methylurea model of mammary carcinogenesis: Potential involvement of antiestrogenic mechanisms in vivo. J. Cancer Res. Clin. Oncol. 117, 526 (1991)

38. P. Kubatka, B. Bojková, K. Môciková-Kalická, M. MníchováChamilová, E. Adámeková, I. Ahlers, E. Ahlersová, M. Čermáková, Effects of tamoxifen and melatonin on mammary gland cancer induced by N-methyl-N-nitrosourea and by 7,12-dimethylbenz(a)anthracene, respectively, in female sprague-dawley rats. Folia Biol. (Praha) 47, 5 (2001)

39. N. do, N. Gonçalves, J. Colombo, J.R. Lopes, G.B. Gelaleti, M.G. Moschetta, N.M. Sonehara, E. Hellmén, C. de, F. Zanon, S.M. Oliani, D.A.P. de C. Zuccari, Effect of melatonin in epithelial mesenchymal transition markers and invasive properties of breast cancer stem cells of canine and human cell lines. PLoS ONE 11, e0150407 (2016)

40. L. Mao, L. Yuan, L.M. Slakey, F.E. Jones, M.E. Burow, S.M. Hill, Inhibition of breast cancer cell invasion by melatonin is mediated through regulation of the p38 mitogen-activated protein kinase signaling pathway. Breast Cancer Res. 12, R107 (2010)

41. P. Orendáš, P. Kubatka, B. Bojková, M. Kassayová, K. Kajo, D. Výbohová, P. Kružliak, M. Péč, M. Adamkov, A. Kapinová, K. Adamicová, V. Sadloňová, M. Chmelová, N. Stollárová, Melatonin potentiates the anti-tumour effect of pravastatin in rat mammary gland carcinoma model. Int. J. Exp. Pathol. 95, 401 (2014)

42. K.M. Eck, L. Yuan, L. Duffy, P.T. Ram, S. Ayettey, I. Chen, C.S. Cohn, J.C. Reed, S.M. Hill, A sequential treatment regimen with melatonin and all-trans retinoic acid induces apoptosis in MCF-7 tumour cells. Br. J. Cancer 77, 2129 (1998)

43. K. Melancon, Q. Cheng, T.L. Kiefer, J. Dai, L. Lai, C. Dong, L. Yuan, A. Collins, A. Thiyagarajah, S. Long, S.M. Hill, Regression of NMU-induced mammary tumors with the combination of melatonin and 9-cis-retinoic acid. Cancer Lett. 227, 39 (2005)

44. S.S. Moselhy, M.A.B. Al mslmani, Chemopreventive effect of lycopene alone or with melatonin against the genesis of oxidative stress and mammary tumors induced by 7,12 dimethyl(a)benzanthracene in sprague dawely female rats. Mol. Cell. Biochem. 319, 175 (2008)

45. E.A. De Almeida, P. Di Mascio, T. Harumi, D.W. Spence, A. Moscovitch, R. Hardeland, D.P. Cardinali, G.M. Brown, S.R. Pandi-Perumal, Measurement of melatonin in body fluids: Standards, protocols and procedures. Child's Nerv. Syst. 27, 879 (2011)

46. D. Acuña-Castroviejo, G. Escames, C. Venegas, M.E. DíazCasado, E. Lima-Cabello, L.C. López, S. Rosales-Corral, D.-X. Tan, R.J. Reiter, Extrapineal melatonin: Sources, regulation, and potential functions. Cell. Mol. Life Sci. 71, 2997 (2014)

47. W.H. Talib, S. Saleh, Propionibacterium acnes augments antitumor, anti-angiogenesis and immunomodulatory effects of melatonin on breast cancer implanted in mice. PLoS ONE 10, e0124384 (2015)

48. W. Ren, G. Liu, S. Chen, J. Yin, J. Wang, B. Tan, G. Wu, F.W. Bazer, Y. Peng, T. Li, R.J. Reiter, Y. Yin, Melatonin signaling in T Cells: functions and applications. J. Pineal Res. 62, 1 (2017)

49. A. González-González, M.D. Mediavilla, E.J. Sánchez-Barceló., Melatonin, A molecule for reducing breast cancer risk. Molecules 23, 336 (2018) 
50. P.J. Lardone, A. Carrillo-Vico, M.C. Naranjo, B. De Felipe, A. Vallejo, M. Karasek, J.M. Guerrero, Melatonin synthesized by jurkat human leukemic $\mathrm{T}$ cell line is implicated in IL-2 production. J. Cell. Physiol. 206, 273 (2006)

51. H. Zhang, Y. Zhang., Melatonin: A well-documented antioxidant with conditional pro-oxidant actions. J. Pineal Res. 57, 131 (2014)

52. Y. Chen, M. Leon-Ponte, S.C. Pingle, P.J. O'Connell, G.P. Ahern, T lymphocytes possess the machinery for 5-HT synthesis, storage, degradation and release. Acta Physiol. (Oxf.). 213, 860 (2015)

53. F. Fallarino, U. Grohmann, K.W. Hwang, C. Orabona, C. Vacca, R. Bianchi, M.L. Belladonna, M.C. Fioretti, M.-L. Alegre, P. Puccetti, Modulation of tryptophan catabolism by regulatory T cells. Nat. Immunol. 4, 1206 (2003)

54. P. Terness, T.M. Bauer, L. Röse, C. Dufter, A. Watzlik, H. Simon, G. Opelz, Inhibition of allogeneic $\mathrm{T}$ cell proliferation by indoleamine 2,3-dioxygenase-expressing dendritic cells: Mediation of suppression by tryptophan metabolites. J. Exp. Med. 196, 447 (2002)
55. G.C. Prendergast, C. Smith, S. Thomas, L. Mandik-Nayak, L. Laury-Kleintop, R. Metz, A.J. Muller, Indoleamine 2,3-dioxygenase pathways of pathogenic inflammation and immune escape in cancer. Cancer Immunol. Immunother. 63, 721 (2014)

56. B. Heng, C.K. Lim, D.B. Lovejoy, A. Bessede, L. Gluch, G.J. Guillemin, Understanding the role of the kynurenine pathway in human breast cancer immunobiology. Oncotarget 7, 6506 (2016)

57. D.E. Carvajal-Hausdorf, N. Mani, V. Velcheti, K.A. Schalper, D. L. Rimm, Objective measurement and clinical significance of IDO1 protein in hormone receptor-positive breast cancer. J. Immunother. Cancer 5, 81 (2017)

58. A. Leja-Szpak, P. Pierzchalski, M. Goralska, K. Nawrot-Porabka, J. Bonior, P. Link-Lenczowski, M. Jastrzebska, J. Jaworek, Kynuramines induce overexpression of heat shock proteins in pancreatic cancer cells via 5-hydroxytryptamine and MT1/MT2 receptors. J. Physiol. Pharmacol. 66, 711 (2015) 